\title{
Heart Rate Variability in Patients with Rheumatoid Arthritis
}

\author{
Kawser Jahan', Noorzahan Begum², Sultana Ferdousi ${ }^{3}$
}

\begin{abstract}
Background: Altered cardiovascular autonomic nerve function with impaired sympathovagal balance is found in rheumatoid arthritis (RA). Heart Rate Variability (HRV) analysis is an important tool for assessment of autonomic nerve activity. Objective: To assess cardiac autonomic nerve function status in patients with Rheumatoid arthritis (RA) by time domain measures of HRV. Methods: This cross sectional study was conducted in the Department of Physiology, Bangabandhu Sheikh Mujib Medical University (BSMMU), Dhaka from January to December 2010. Sixty female RA patients, age range 18-50 years were constituted study group enrolled from the Out- patient Rheumatology Wing, Department of Medicine, BSMMU. Age matched thirty apparently healthy females were studied as control. Time domain measures of Heart Rate Variability (HRV) such as Mean RR intervals, Mean HR, SDNN, RMSSD, NN50\% and PNN 50\% were recorded for 5 minutes by a Polygraph machine to observe cardiac autonomic nerve function activity. Data were analyzed by independent sample $t$ test. Results: Mean R-R interval, SDNN, RMSSD, PNN50\%, NN50\% were significantly lower ( $<<0.001)$ but heart rate was significantly $(\mathrm{P}<0.001)$ higher in rheumatoid arthritis patients. Conclusion: Cardiac autonomic nerve function is impaired and characterized by reduced resting parasympathetic activity in female Rheumatoid Arthritis patients.
\end{abstract}

Key words: RA, HRV, SDNN, RMSSD, PN50\%, NN50\%.

J Bangladesh Soc Physiol. 2012 December; 7(2): 78-82 For Authors Affiliation, see end of text.

http://www.banglajol.info/index.php/JBSP

\section{Introduction}

$\mathbf{R}$

heumatoid arthritis (RA) is a systemic inflammatory autoimmune disease ${ }^{1}$.

This connective tissue order was found to affect various organs including cardiovascular system $^{2,3}$. Nearly half of the deaths with RA were attributed to cardiovascular involvement ${ }^{1,3,4}$.

Involvement of cardiac tissue in RA suggested to encompass both autonomic components and result in sympathovagal imbalance ${ }^{2,5,6}$.

Balance between sympathetic and parasympathetic nervous system reflects the variation of normal heart rate ${ }^{2}$. Quantitative and

Received : July 2012; $\quad$ Accepted: October 2012 qualitative interpretation of sympathovagal modulation of cardiovascular function can be achieved by HRV analysis. This analysis is a widely accepted sensitive marker for sympathetic and parasympathetic nerve function activity 2,5 .

Reduced HRV may be associated with increased mortality in patients with RA. ${ }^{2}$ Involvement of autonomic nervous system in patients with RA has so far not been studied in Bangladeshi origin $^{2,5}$.

Time domain method records the heart rate at any point of time or the intervals between successive QRS complex in a continuous ECG record. Common simple time domain variables 
include the mean normal-to-normal QRS complex (NN) interval and the mean heart rate. Statistical time domain variables include the standard deviation of the $\mathrm{NN}$ interval (SDNN) and the square root of the mean squared differences of successive NN intervals (RMSSD), NN50\%, and PNN50\% 7 .

SDNN and RMSSD represent a general measurement of autonomic nervous system balance or estimates of overall HRV. Again, PNN50\% reflects parasympathetic activity ${ }^{2,7}$.

Lower values of mean R-R interval and higher values of mean heart rate were mentioned by some investigators in patients with rheumatoid arthritis when compared with those of healthy control $^{2,6,8-10}$.

Again, lower values of SDNN, RMSSD and PNN50\% were reported by various investigators of different countries in patients with rheumatoid arthritis in comparison with those of healthy control $^{6,8,9}$.

On the contrary, higher RMSSD, PNN50\% were observed by some investigators in patients with RA when compared with those of healthy control $^{2}$.

In Bangladesh, the prevalence of RA is about $1 \%$ and is attributed to severe joint morbidity and various other organ dysfunction ${ }^{11}$. Although a cardiac involvement is silent ${ }^{3}$, it is possible to prevent the development of various cardiac complications in this group of patients by evaluating cardiac autonomic nerve function status.

Therefore, the purpose of the study was to assess cardiac autonomic nerve function status in RA patients by evaluating HRV. This study may throw some light about the silent existence of autonomic nerve dysfunction and cardiovascular disorders in RA patients and may help the clinicians to minimize the risk of cardiac autonomic impairment related complications.
Therefore, the present study was carried out to explore the autonomic nerve function status in rheumatoid arthritis patients by analyzing HRV by time domain method.

\section{Methods}

This cross sectional study was carried out to observe the HRV by time domain method in 60 female RA patients age range 18 to 50 years, in the Department of Physiology, Bangabandhu Sheikh Mujib Medical University (BSMMU), Dhaka from January 2010 to December 2010. As female were 2-3 times more affected than male ${ }^{12-14}$, they were selected as case. Rheumatoid Arthritis was diagnosed according to American College of Rheumatology (ACR) classification ${ }^{13,15}$.

RA patients (Group B, $n=60$ ) were enrolled in the study from the Out-patient Rheumatology Wing, Department of Medicine, BSMMU, Dhaka. Age and BMI matched apparently healthy females (Group A, n=30) were studied as controls. All the subjects were free from hypertension, heart disease, diabetes mellitus, renal diseases and psychic disorders. Subjects with pregnancy and habit of smoking were excluded.

Detail procedure of study was explained and an informed written consent was taken from each subject. The subjects were advised to have their meal by 9:00 pm on the previous night, not to take sedatives or any drugs affecting central nervous system, to have sound sleep at night before the test and also advised to evade any situation which may excite physical or mental stress.

They were advised to have light breakfast and no tea or coffee. The test was done in the Autonomic Nerve Function Laboratory in the Department of Physiology,BSMMU between 9:00 to 11:00 a.m. Before test, detail personal, drug and medical history were taken.HRV was recorded by using standard lead II of the ECG channel of a digital Polyrite machine and a 5 minutes recording was taken at resting state in supine position. Time domain parameters of Heart Rate Variability such as mean R-R interval, mean heart rate, SDNN, 
RMSSD, NN50\%, PNN50\% were measured by a polygraph (RMS Polyrite D, version 2.2). Data was analyzed by Independent sample t-test by using software of SPSS-12.

\section{Results}

Basal characteristics of the subjects were presented in table I. The mean resting pulse rate $(\mathrm{p}<0.05), \mathrm{DBP}(\mathrm{p}<0.001)$ were significantly higher and mean SBP relatively higher $(p>0.05)$ in RA patients compared to control. The mean R-R interval was significantly $(\mathrm{p}<0.05)$ lower but mean heart rate was significantly $(\mathrm{p}<0.05)$ higher in $\mathrm{RA}$ patients (Table II). Mean values of SDNN, RMSSD, NN50\% and PNN50\% were significantly $(\mathrm{p}<0.001)$ lower in RA patients (Table III).

Table I : Baseline characteristics in different groups $(\mathrm{n}=90)$

\begin{tabular}{lccc}
\hline Variables & Group $\mathrm{A}(\mathrm{n}=30)$ & Group B $(\mathrm{n}=60)$ & $\mathrm{p}$ values \\
\hline Age $($ years $)$ & $36.50 \pm 11.50$ & $37.09 \pm 11.10$ & $0.803^{\mathrm{ns}}$ \\
BMI $\left(\mathrm{Kg} / \mathrm{m}^{2}\right)$ & $23.88 \pm 2.27$ & $23.94 \pm 1.68$ & $0.876^{\mathrm{ns}}$ \\
Pulse $($ beat $/ \mathrm{min})$ & $80.29 \pm 10.62$ & $85.34 \pm 11.22$ & $0.03^{*}$ \\
SBP $(\mathrm{mm}$ of $\mathrm{Hg})$ & $114.37 \pm 11.79$ & $116.19 \pm 11.30$ & $0.451^{\mathrm{ns}}$ \\
DBP $(\mathrm{mm}$ of $\mathrm{Hg})$ & $68.70 \pm 7.59$ & $73.77 \pm 7.01$ & $0.001^{* * *}$ \\
\hline
\end{tabular}

Data were expressed as mean \pm SD. Statistical analysis was done by Independent sample t-test. Group A: Apparently healthy people. Group B: Patients with Rheumatoid arthritis BMI=Body Mass index, SBP=Systolic blood pressure, $\mathrm{DBP}=$ Diastolic blood pressure. ${ }^{* *}=\mathrm{p}<0.01,{ }^{*}=\mathrm{p}<0.05, \mathrm{~ns}=\mathrm{p}>0.05, \mathrm{n}=$ number of subjects. ns=nonsignificant

Table II: Simple time domain parameters of HRV in two groups $(\mathrm{n}=90)$

\begin{tabular}{lccc}
\hline Variables & Group A $(\mathrm{n}=30)$ & Group B $(\mathrm{n}=60)$ & $\mathrm{p}$ values \\
\hline Heart rate (beat/min) & $80.00 \pm 6.96$ & $88.65 \pm 12.58$ & $0.001^{* *}$ \\
Mean R-R (sec) & $0.71 \pm 0.12$ & $0.58 \pm 0.04$ & $0.001^{* *}$ \\
\hline
\end{tabular}

Data were expressed as Mean \pm SD. Statistical analysis was done by Independent sample t test. Group A: Apparently healthy people. Group B: Patients with Rheumatoid arthritis. R-R interval = Interval between successive $\mathrm{QRS}$ complex $(\mathrm{sec}), * *=\mathrm{p}<0.01, \mathrm{n}=$ number of subjects. $\mathrm{ns}=$ nonsignificant

Table III: Statistical time domain parameters of HRV in two groups ( $\mathrm{n}=90)$

\begin{tabular}{lccc}
\hline Variables & Group A $(\mathrm{n}=30)$ & Group B $(\mathrm{n}=60)$ & $\mathrm{p}$ values \\
\hline SDNN $(\mathrm{ms})$ & $76.06 \pm 42.41$ & $47.47 \pm 35.37$ & $0.000 * * *$ \\
RMSSD $(\mathrm{ms})$ & $91.48 \pm 36.73$ & $52.82 \pm 21.84$ & $0.000 * * *$ \\
NN50 $(\%)$ & $82.03 \pm 52.97$ & $26.87 \pm 32.31$ & $0.000^{* * *}$ \\
PNN50 $(\%)$ & $21.65 \pm 16.17$ & $6.03 \pm 9.42$ & $0.000 * * *$ \\
\hline
\end{tabular}

Data were expressed as Mean \pm SD. Statistical analysis was done by Independent sample $t$ test. Group A: Apparently healthy people. Group B: Patients with Rheumatoid arthritis. SDNN= Standard deviation of NN interval, RMSSD $=$ Square root of mean squared differences between adjacent $\mathrm{NN}$ intervals, $\mathrm{NN} 50 \%=$ number of interval differences of successive NN intervals greater than $50 \mathrm{~ms}, \mathrm{PNN} 50 \%=$ number of R-R interval differing by $>50 \mathrm{~ms}$ from adjacent intervals divided by the total number of all $\mathrm{R}-\mathrm{R}$ intervals, $\mathrm{ms}=$ millisecond, $* * *=$ $\mathrm{p}<0.001, \mathrm{n}=$ number of subjects. 


\section{Discussion}

In this study HRV parameters in the healthy control group were within normal range and also similar to that of other reports from abroad $2,6,8$, 9 and at home ${ }^{16,17,18 .}$

Significantly higher resting pulse rate and diastolic blood pressure in the RA patients may be attributed to the lower parasympathetic higher sympathetic activity which is consistent with the observation made by Sandhu and Allen ${ }^{19}$.

There were lower mean R-R interval and higher mean heart rate in the RA group compared to the controls. This feature is postulated to the reduction of vagal modulation and side by side higher sympathetic activity. The findings of the present study confirm the sympathovagal imbalance which was also observed by other researchers ${ }^{2,}$, 8-10.

Lower values of SDNN and RMSSD in the present study indicate decreased overall variability of heart rate in RA patients compared to that of healthy controls. Number of studies reported lower values of SDNN in RA patients ${ }^{2,6,8}$ ${ }^{9}$.Regarding RMSSD values there are conflicting reports. Anichcov et al. (2007) observed lower value of RMSSD where as others rather found higher values ${ }^{12,16}$.

Determination of PNN50\% demonstrates parasympathetic activity at cardiac level. A lower value of PNN50\% indicates low parasympathetic activity in the present study. Although this is consistent with the report of Milovanoviæ et al ${ }^{9}$ but quite contrast to another study ${ }^{2}$.which suggests that validity of PNN50\% value in RA still to be clearly understood.

Many explanations are suggested by different investigators regarding the change of autonomic nerve function activity in RA patients though the exact mechanisms are still to be clearly understood. However, it is assumed that, a consequence of chronic inflammatory process immune complex deposition, amyloid deposition, autoantibody production against nerve growth factor, cervical ganglia and vagus nerve may aggravate the autonomic nerve function impairment in RA patients ${ }^{5,19,20}$. Since RA is an inflammatory condition, vasculitis may also be responsible for autonomic impairment in this group of patients as suggested by others ${ }^{21}$. The exact mechanisms responsible for the impairment of autonomic nerve function in patients with RA could not be elucidated from this study. However, to explore the pathophysiological basis of the development of autonomic nerve dysfunction in RA further in depth studies are required involving both $\mathrm{RA}$ patients and appropriate animal model.

\section{Conclusion}

From this study, it can be concluded that cardiac autonomic nerve function is impaired in rheumatoid arthritis which is characterized by reduced parasympathetic with higher sympathetic activity.

\section{Author affiliations}

1. *Kawser Jahan, Assistant professor, Department of Physiology, Shahid Monsur Ali Medical College, Ka95/1Kuril Bishaw Road, Dhaka-1229. Email: kawserjahan64@yahoo.com

2. Noorzahan Begum, Professor, Department of Physiology, Bangabandhu Sheikh Mujib Medical University (BSMMU) Bangladesh. Email: noorzahan52@gmail.com

3. Sultana Ferdousi, Associate professor, Department of Physiology, Bangabandhu Sheikh Mujib Medical University(BSMMU) Bangladesh. Email: sferdousiratna@gmail.com

*For correspondence,

\section{References}

1. Kremers HM, Crowson CS, Therneau TM, Roger VL, Gabriel SE. High ten-year risk of cardiovascular disease in newly diagnosed rheumatoid arthritis patients: a population-based cohort study. Arthritis Rheum 2008; 58: 2268-74.

2. Evrengül H, Dursunoglu D, Cobankara V, Polat B, Seleci D, Kabukeu S, Kaftan A, Semiz E, Kilic M. Heart rate variability in patients with rheumatoid arthritis. Rheumatol Int 2004; 24:198-202.

3. Gerli $\mathrm{R}$ and Goodson NJ. Cardiovascular involvement in rheumatoid arthritis. Lupus 2005; 14:679. 
4. Kitas GD and Erb N. Tackling ischemic heart disease in rheumatoid arthritis. Rheumatology 2003; 42:607-13

5. Louthrenoo W, Ruttanaumpawan P, Aramrattana A and Sukitawut W. Cardiovascular autonomic nervous system dysfunction in patients with rheumatoid arthritis and systemic lupus erythematosus. Q J Med 1999; 92:97-102.

6. Kamal A. Assessment Of Autonomic function in patients with rheumatoid arthritis using spectral analysis 7 approximate entropy method. Neurosciences 2007; 12(2): 136-39.

7. Task force of the European society of cardiology and the north American society of pacing and electrophysiology, heart rate variability.Standards of measurement, physiological interpretation and clinical use. Circulation 1996; 93:1043-65.

8. Anichkov DA, Shostak NA, Ivanov DS. Heart rate variability is related to disease activity and smoking in rheumatoid arthritis patients. Int J Clin Pract 2007; 61: 777-83.

9. Milovanoviæ B, Stojannoviæ L, Miliæeviæ L, Vasiæ K, Bjelakoviæ B, Krotin M. Cardiac autonomic dysfunction in patients with systemic lupus, rheumatoid arthritis and sudden cardiac risk. Srp Arh Celok Lek 2010; 138: 26-32.

10. Bidikar MP and Ichaporia RB. Autonomic (sympathetic) nervous system involvement in rheumatoid arthritis patients. Indian J Physiol Pharmacol 2010; 54(1):73-79.

11. Statistics By Country For Rheumatoid Arthritis.[Internet] March 2005[Cited 2011] Available From: http://www.cureresearch.com/r/ rheumatoid_arthritis/stats-country_printer.htm

12. Akil M and Amos RS. ABC of Rheumatology: Rheumatoid Arthritis-I: clinical features and diagnosis. BMJ 1995; 310: 587-90.

13. Altman RD. Rheumatoid Arthritis (RA): Joint Disorders: Merck mannual books of patient symptoms. Porter RS, Kaplan JL, Homeier BP (eds). [Internet]. [Update $2008 \mathrm{Feb}$; Cited 2009 Jun 24] Available From: http://www.merck books.com/symptoms/index.htm

14. Shiel Jr WC. Rheumatoid Arthritis. [Internet] 2010 [Cited 2010 September] Available From: http:// www.emedicinehealth.com/rheumatoid_arthritis/ article_em.htm

15. Arnett FC, Edworthy SM, Bloch DA, McShane DJ, Fries JF, Cooper NS, Healey LA, Kaplan SR, Liang MH, Luthra HS. The American rheumatism association 1987 revised criteria for the classification of rheumatoid arthritis. Arthritis Rheum 1988; 31(3):315-24.

16. Kabir MR. Study On Heart Rate Variability In Patients With Hyperthyroidism. [Thesis][Dhaka (Bangladesh)]:BSMMU.2008.

17. Mithun S. Comparative study of cardiac autonomic nerve function status by heart rate variability between sedentary and heavy workers. [Thesis] [Dhaka (Bangladesh)]: BSMMU.2006 July.

18. Tabassum R. Assessment of cardiac autonomic nerve function status by heart rate variability in essential hypertension.[Thesis] [Dhaka (Bangladesh)]: BSMMU.2008 Jan.

19. Sandhu V and Allen SC. The effects of age, seropositivity and disease duration on autonomic cardiovascular reflexes in patients with rheumatoid arthritis. Int J Clin Pract 2004; 58(8):740-45.

20. Maule S, Quadri R, Mirante D, Pellerito A, Marucco E, Marnone C, Vergani D, Chiandussi L \& Zanone M. Autonomic nervous system dysfunction in systemic lupus erythematosus and rheumatoid arthritis: possible pathogenic role of auto antibodies to autonomic nervous structures. Clin Exp Immunol 1997; 110: 423 -27.

21. Edmonds ME, Jones TC, Saunders WA, Sturrock R. Autonomic Neuropathy In Rheumatoid Arthritis. Br. Med Journal.1979; 2:173-75. 